\title{
The Role Of Intrapartum Ultrasonography In Assessment Of Labor Progression Among Term Women
}

\author{
Maher E. R. Ibrahim ${ }^{1, *}$ M.B.B.CH, Abd-Elmonsef A. Seddik ${ }^{1}$ MD, Awad M. Awad ${ }^{1}$ MD
}

*Corresponding Author:

Maher E. R. Ibrahim

maherrashad2017@gmail.com

Received for publication September 4, 2021; Accepted November 14, 2021; Published online November 14, 2021.

Copyright The Authors published by Al-Azhar University, Faculty of Medicine, Cairo, Egypt. Users have the right to read, download, copy, distribute, print, search, or link to the full texts of articles under the following conditions: Creative Commons Attribution-Share Alike 4.0 International Public License (CC $B Y-S A$ 4.0).

doi: 10.21608/aimj.2021.92115.1556

${ }^{I}$ Obstetrics and Gynecology Department, Faculty of Medicine, Al-Azhar University Cairo, Egypt.

Disclosure: The authors have no financial interest to declare in relation to the content of this article. The Article Processing Charge was paid for by the authors.

Authorship: All authors have a substantial contribution to the article.

\begin{abstract}
Background: Unprompted vaginal labor with no obstetric interventions is the appropriate outcome for the majority of gestations. But some cases fail to develop in the 2nd-stage of labour and therefore need surgical delivery.

Aim of the work: The current work aimed to evaluate the role of ultrasound (US) in labour to determine embryonic head station, dilatation, location and viewpoint.

Patients and methods: This prospective observational investigation has been performed at the obstetrics and gynecology department, at Bab elsharia, Al-azhar University Hospital on 85 women with singleton term ( 37 to 40 -wks) gestations. The study was conducted in the Obstetrics and Gynecology department at Bab el-sharia, Al-azhar University Hospital.

Results: The ultrasonography assessment of cervical dilatation correlated significantly with digital vaginal examination (DVE), there was high significant between the two methods when the Cervical dilation was $4 \mathrm{~cm}$. The intra-class correlation coefficient (ICC) for the 2 approaches US and DVE regarding Cervical expansion presented a high connotation (ICC, $0.98495 \%$ confidence interval [CI], 0.976-0.990) and the accord among DVE and US was Nearly ideal accordance $(\kappa=0.801$, $\mathrm{P}<0.001$ ).

Conclusion: intra-partum US was revealed to be a suitable tool for monitoring labour progress throughout the active phase between term cases. The accordance among DVE and US results was strong for cervical expansion, and reasonable for embryonic head station and head location. The majority of labouring cases revealed that US is less upsetting and favored it over DVE for labour assesses.
\end{abstract}

Keywords: vaginal delivery; Cervical dilation, ultrasonography; intrapartum; embryonic head station and head position.

\section{INTRODUCTION}

Conventionally, the evaluation and management of women in labour is founded on clinical results. ${ }^{1}$

But, clinical examinations of the head station and situation are inexact and subjective, particularly when head succedaneum harms palpation of the fontanels and sutures. ${ }^{2}$

The usage of the US was suggested to help in managing labour. Research has concluded that US investigation is more precise and re-producible than clinical examinations in the embryonic head location and station diagnosing and in the estimate of arrest of labour. ${ }^{3}$

US examinations could, somewhat, differentiate between those cases intended for unprompted vaginal birth and those intended for surgical birth. ${ }^{4}$

Also, there is an increasing suggestion that US labour can expect the outcomes of instrumentally vaginal deliveries. ${ }^{5}$

US in labour could be achieved via a transabdominal method, mostly to find out embryonic head and spine locations, or a trans-perineal method, for evaluation of head station and location at early stations. ${ }^{6}$

\section{PATIENTS AND METHODS}

This prospective observational investigation has been done at the obstetrics and gynecology department, at Bab el-sharia, Al-Azhar University Hospital, on 85 cases with singleton term (37-40 weeks) gestations. The study was conducted in the Obstetrics and Gynecology department at Bab el-sharia, Al-azhar University Hospital.

The study was considered official after the acceptance by the ethical committee of the faculty. The study was carried out on a total of 85 women in active labour. They will be assigned to either the US or digital examination.

Inclusion Criteria: Gravid females aging between 2040-yrs, gestational age of 37-40 weeks, cases with singleton term (37-40-wks) gestations, admittance because of strong steady uterine contractions or to unprompted ruptures of membranes, and cases with intact membranes who were in the active stage of labour were as well involved. 
Exclusion Criteria: cases with breech presentations preceding secarean sections, patients with multiple pregnancies, placenta previa and preterm pregnancies.

\section{METHODS}

Methods of diagnosis

History taking: Personal date: (Name, age, sex, address, phone number, occupation).

The patient will be examined systematically for any other associated injuries.

All patients will be subjected to the following: Afterward, attaining a written agreement, DVEs and US will be done nearly at the same time. The digital examination was done by a senior obstetrician with greater than 10-yrs of clinical experience. US examinations will be performed. The results of each inspector have been documented in their own report, and the inspectors will be unaware of the findings of each other.

Technique: US assessments in labour can be done using a trans-abdominal or trans-perineal method, based on the parameters that are the objective of the examinations (principally location and station) and on the clinical indications.

Assessments of embryonic head location: Sonographic assessments of embryonic head location are best done via trans-abdominal scanning in the axial and sagittal planes.

Assessments of embryonic head station: Sonographic assessments of the embryonic head station are best done by trans-perineal US in the midsagittal or axial planes.

Assessments of embryonic head attitudes: The embryonic head attitude is the connection between the embryonic head and the spine.

Assessment of cervical dilation: Cervical expansion was calculated at 2 levels by maintaining the pointers on the internal rim of the cervix on each side, and the mean of the 2 remarks has been recorded.

Statistical analysis: the collected data was analyzed via the windows IBM-SPSS-20.0. (Armonk, NY: IBM Corp) Qualitative data has been presented as numbers and percentages. The Kolmogorov-Smirnov test has been employed to find out the normality of distributions. Quantitative data has been presented as range (min and max), mean and standard deviation (SD). The significance of the findings was considered at the level of $5 \%$.

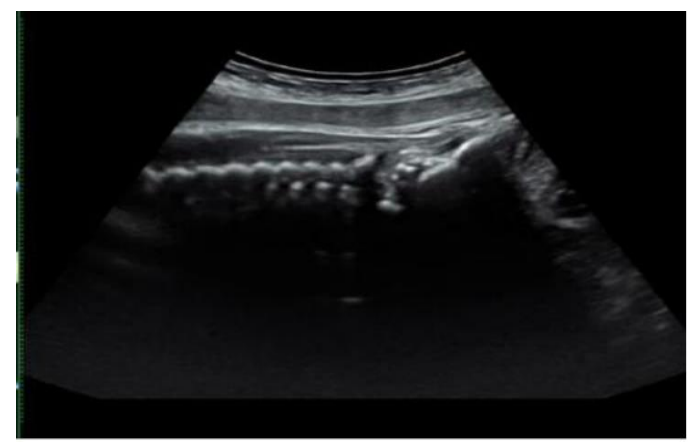

Fig. 1: Transabdominal ultrasound imaging (sagittal plane) in fetus with occiput-anterior position

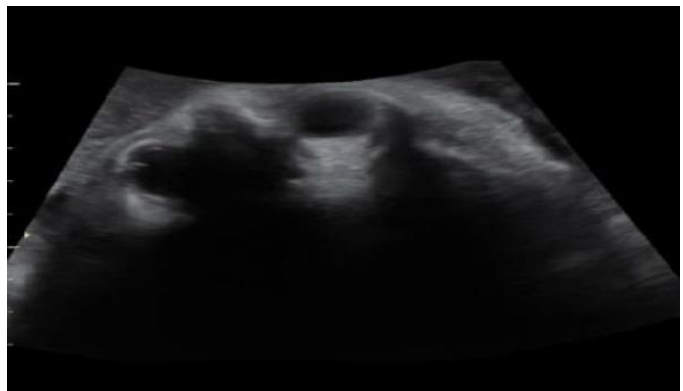

Fig. 2: Transabdominal ultrasound imaging (transverse plane) in fetus with occiput-posterior position

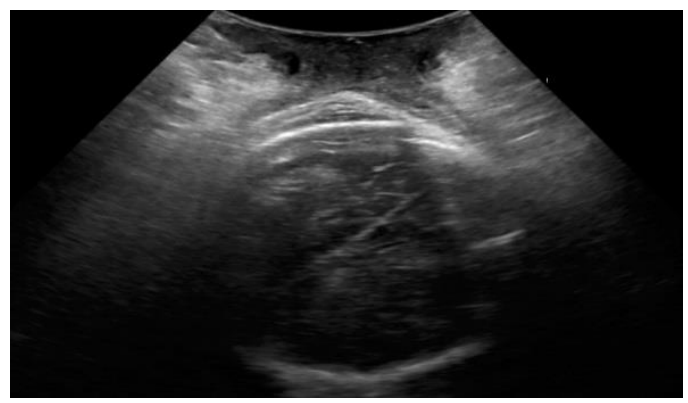

Fig. 3: Transverse transperineal image (frontal plane related to woman) illustrating measurement of headperineum distance

\section{RESULTS}

The age of the study group females ranged between 23 and 40-yrs, with a Mean SD of 31.875.131. Their weight range was 58-97 and the Mean SD was $78.8212 .063 \mathrm{~kg}$. Their height range was $156-187$ and the Mean SD was $172.219 .203 \mathrm{~cm}$, with a BMI range of 17.13-39.45 and 26.825.09. The females' residence was almost equally distributed, where $41(48.2 \%)$ were rural and $44(51.8 \%)$ were urban. The gestational age was distributed as $20(23.5 \%)$ in the 37 th week, 26 (30.6) in the 38th week, 20 (23.5\%) in the 39th week, and $19(22.4 \%)$ in the 40th week. As regards the birthweight of the newborns, $62(72.9 \%)$ were between 2.5 and $3.5 \mathrm{~kg}$, and $23(27.1 \%)$ were above $3.5 \mathrm{~kg} .6(7.1 \%)$ of the females gave birth by cesarean section, and $79(92.9 \%)$ by Vaginal Delivery.

The embryonic head position distribution in the study group females according to ultrasonography and DVE examination and the agreement between them. The embryonic head position couldn't be identified in $21(24.7 \%)$ of the females by the DVE examination. There was high agreement $(78.1 \%)$ between the two methods when the embryonic head location was LOA-Left Occiput Frontal. The ICC for the 2 ways US and DVE as regards Embryonic head position revealed a high correlation (ICC, 0.669 95\% CI, 0.492-0.785) and the association between DVE and US was significant ( $=0.635, \mathrm{P} 0.001)$. Figure (4)

The embryonic head station distribution in the study group females according to ultrasonography and DVE examination and the agreement between them. There was high agreement $(95 \%)$ between the two methods when the embryonic head station was 20$\mathrm{mm}$. The ICC for the 2 approaches to US and DVE 
as regards embryonic head station revealed a high correlation (ICC, $0.98095 \%$ CI, 0.969-0.987) and the accordance between DVE and US was fair $(=0.378$, P-value 0.001).

The embryonic head station distribution in the study group females according to ultrasonography and DVE examination and the agreement between them. There was high agreement (100\%) between the two methods when the embryonic head attitude was up. The ICC for both US and DVE as regards embryonic head attitude revealed a high correlation (ICC, 0.944 95\% CI, 0.914-0.964) and the accordance between DVE and US was almost perfect agreement $(=0.894$, P 0.001).

The Cervical dilation distribution in the study group females according to ultrasonography and DVE examination and the agreement between them. There was high agreement (93.8\%) between the 2 approaches when the cervical dilation was $4 \mathrm{~cm}$. The ICC for the two methods, US and DVE, as regards cervical dilation, revealed a high correlation (ICC, 0.984 95\% CI, 0.976-0.990) and the accordance between DVE and US was almost perfect agreement $(=0.801, \mathrm{P}$-value 0.001$)$.

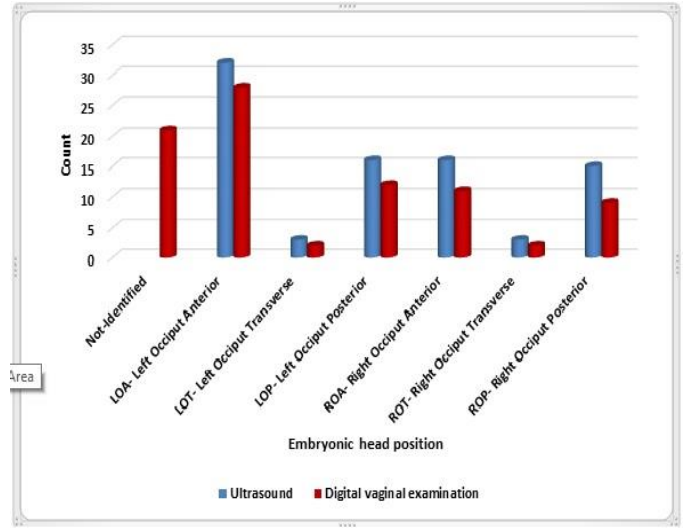

Fig. 4: Fetal head location distribution in the study group females

\begin{tabular}{|c|c|c|}
\hline \multicolumn{3}{|c|}{ Characteristic Value $(n=85)$} \\
\hline \multicolumn{3}{|l|}{ Age (Year) } \\
\hline Range & \multicolumn{2}{|c|}{$23-40$} \\
\hline Mean \pm SD & \multicolumn{2}{|c|}{$31.87 \pm 5.131$} \\
\hline \multicolumn{3}{|l|}{ Weight(Kg.) } \\
\hline Range & \multicolumn{2}{|c|}{$58-97$} \\
\hline Mean \pm SD & \multicolumn{2}{|c|}{$78.82 \pm 12.063$} \\
\hline \multicolumn{3}{|l|}{ Height(Cm.) } \\
\hline Range & \multicolumn{2}{|c|}{$156-187$} \\
\hline Mean \pm SD & \multicolumn{2}{|c|}{$172.21 \pm 9.203$} \\
\hline \multicolumn{3}{|l|}{ BMI } \\
\hline Range & \multicolumn{2}{|c|}{$17.13-39.45$} \\
\hline \multirow[t]{2}{*}{ Mean \pm SD } & \multicolumn{2}{|c|}{$26.82 \pm 5.09$} \\
\hline & Frequency & Percent \\
\hline \multicolumn{3}{|l|}{ Residence } \\
\hline Rural & 41 & $48.2 \%$ \\
\hline Urban & 44 & $51.8 \%$ \\
\hline \multicolumn{3}{|c|}{ Gestational age (week +days) } \\
\hline $37+0-37+6$ & 20 & $23.5 \%$ \\
\hline $38+0-38+6$ & 26 & $30.6 \%$ \\
\hline $39+0-39+6$ & 20 & $23.5 \%$ \\
\hline $40+0-40+6$ & 19 & $22.4 \%$ \\
\hline \multicolumn{3}{|l|}{ Birthweight(kg) } \\
\hline $2.5-3.5$ & 62 & $72.9 \%$ \\
\hline$>3.5$ & 23 & $27.1 \%$ \\
\hline \multicolumn{3}{|l|}{ Type of labor } \\
\hline cesarean section & 6 & $7.1 \%$ \\
\hline Vaginal Delivery & 79 & $92.9 \%$ \\
\hline
\end{tabular}

Table (1): Characteristics of the study group females

\begin{tabular}{ccccccc}
\hline Fetal head station (cm) & Ultrasound & \multicolumn{3}{c}{ Digital vaginal examination } & \multicolumn{2}{c}{ Agreement } \\
\cline { 2 - 6 } & $\mathrm{N}$ & $\%$ & $\mathrm{~N}$ & $\%$ & $\mathrm{~N}$ & $0.0 \%$ \\
$\mathbf{- 5}$ & 0 & $0.0 \%$ & 1 & $1.2 \%$ & 0 & $50.0 \%$ \\
$-\mathbf{4 -}$ & 8 & $9.4 \%$ & 5 & $5.9 \%$ & 4 & $37.5 \%$ \\
$\mathbf{- 3}$ & 8 & $9.4 \%$ & 7 & $15 \%$ & 3 & $75.0 \%$ \\
$\mathbf{- 2}$ & 12 & $14.1 \%$ & 13 & $15.3 \%$ & 9 & $57.1 \%$ \\
$-\mathbf{- 1 -}$ & 7 & $8.2 \%$ & 7 & $8.2 \%$ & 4 & $12.5 \%$ \\
$\mathbf{0}$ & 8 & $9.4 \%$ & 4 & $4.7 \%$ & 1 & $60.0 \%$ \\
\hline $\mathbf{1}$ & 5 & $5.9 \%$ & 12 & $14.1 \%$ & 3 & \\
\hline
\end{tabular}




\begin{tabular}{|c|c|c|c|c|c|c|}
\hline 2 & 9 & $10.6 \%$ & 14 & $16.5 \%$ & 4 & $44.4 \%$ \\
\hline 3 & 17 & $20.0 \%$ & 12 & $14.1 \%$ & 6 & $35.3 \%$ \\
\hline 4 & 11 & $12.9 \%$ & 7 & $8.2 \%$ & 4 & $36.4 \%$ \\
\hline 5 & 0 & $0.0 \%$ & 3 & $3.5 \%$ & 0 & $0.0 \%$ \\
\hline Total & 85 & 100.0 & 85 & 100.0 & 38 & $44.7 \%$ \\
\hline \multicolumn{4}{|c|}{ Measure of Agreement Kappa } & & \multicolumn{2}{|l|}{ P-value } \\
\hline \multicolumn{4}{|c|}{0.378} & & \multicolumn{2}{|l|}{$0.000 * *$} \\
\hline \multirow{2}{*}{\multicolumn{2}{|c|}{ Interclass Correlation (ICC) }} & \multicolumn{2}{|c|}{ CI(95\%) } & & \multirow{2}{*}{\multicolumn{2}{|c|}{ P-value }} \\
\hline & & Upper & Lower & & & \\
\hline \multicolumn{2}{|l|}{0.980} & 0.969 & 0.987 & & \multicolumn{2}{|l|}{$0.000 * *$} \\
\hline
\end{tabular}

Table (2): Fetal head station distribution in the study group females according to ultrasonography and DVE examination

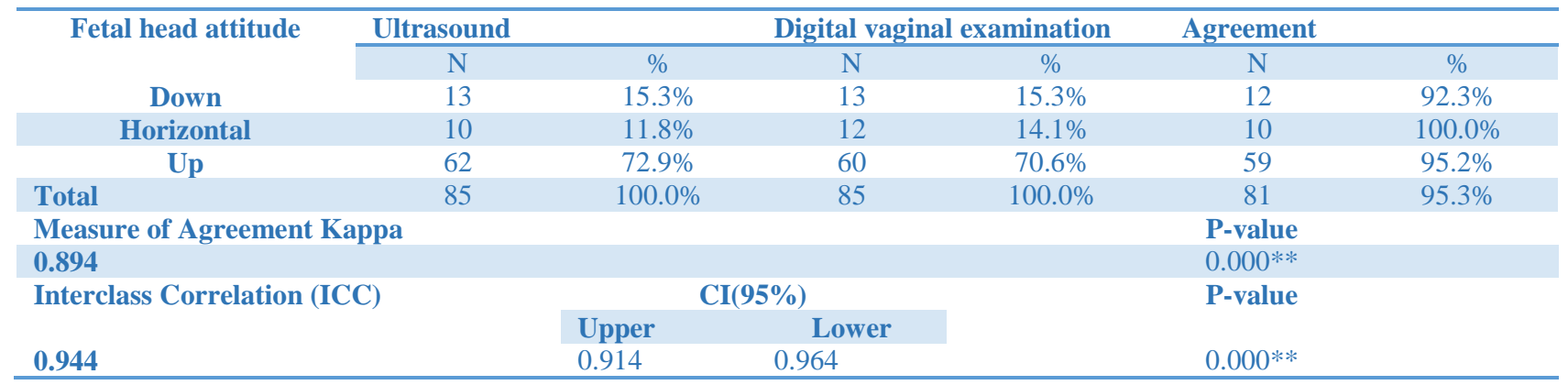

Table (3): Fetal head position attitude distribution in the study group females according to ultrasonography and DVE examination

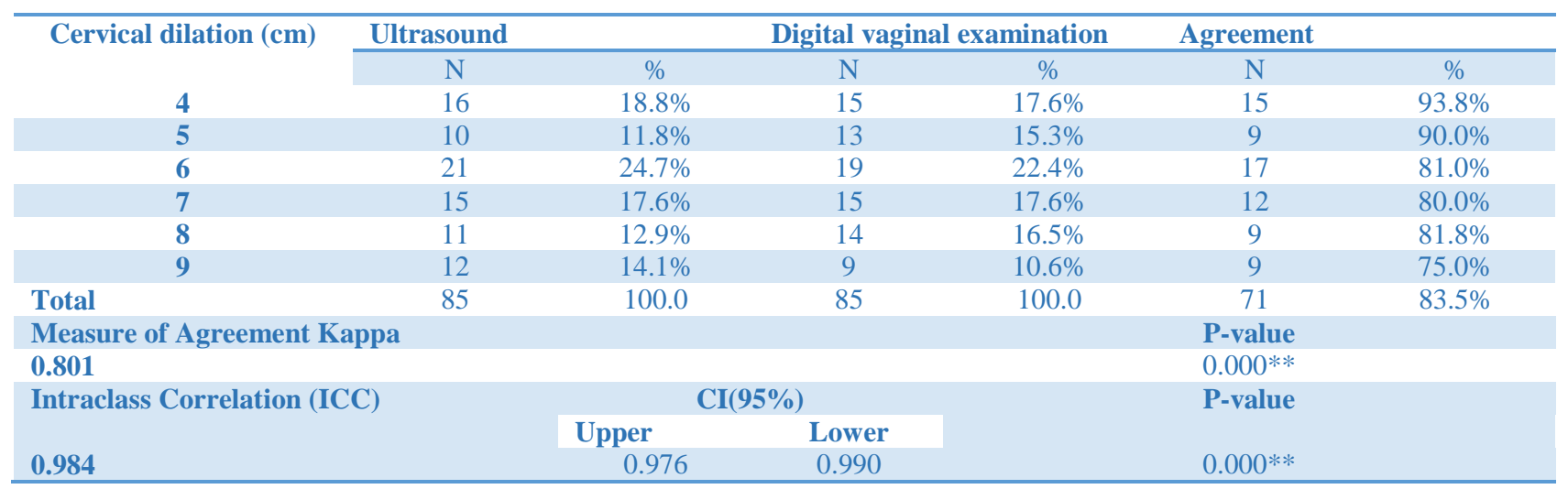

Table (4): Cervical dilation distribution in the study group females according to ultrasonography and DVE examination

\section{DISCUSSION}

Labor progress monitoring is important to avoid embryonic and maternal complications. There are massive variations in the period of labour between females. It is suggested that females must be permitted to labour for extended periods so that vaginal birth can be done. ${ }^{7}$

Conventionally, the evaluation and management of a female in labour is built on clinical results. The labour arrest diagnosis and decisions concerning the timing or type of intervention rely mostly on digital evaluation of cervical dilatation and embryonic head station and location. But, clinical examinations of the head station and location are inexact and particular, especially when head succedaneum harms palpation of the joints and fontanelles. ${ }^{5}$

US examinations could, somewhat, differentiate between those females intended for unprompted vaginal birth and those intended for operational deliveries. Moreover, there is a rising suggestion that US labour can expect the outcomes of instrumentally vaginal deliveries. ${ }^{8}$

The current work aimed to assess the role of the US in labour to find out about embryonic head station, dilatation, location and attitudes.

This was a prospective observational investigation was done at the obstetrics and gynecology department at Bab el-sharia, Al-Azhar University Hospital on 85 women with singleton term (37-40 weeks) pregnancies.

This comes in comparison with the study of Mohan et al., ${ }^{7}$ in which 215 -cases were involved. Amongst these cases, 20 were born after the $1^{\text {st }}$ labour evaluation, 162 afterward the $2^{\text {nd }}, 18$ afterward the $3^{\text {rd }}$, and 15 afterward the $4^{\text {th }}$. Consequently, a number of 458 observations have been attained by DVE as well as the US. The age mean was 23.1 2.7-yrs, and the mean pregnancy age was 383-wks. It was unprompted for $173(80.4 \%)$ cases and persuaded 
because of motherly and embryonic indications for $42(19.5 \%)$ females. BMI was $18.5-22.9$ in 148 (68.8), and was 23.0-24.9 in 57 (26.5). There were $11(5.1 \%)$ operational vaginal births and $6(2.7 \%)$ cesarean births. The percentage of cesarean deliveries was less than that of the studied group $(28 \%)$ because of the studied cases of low-risk nulliparous females in active labour, whereas 159 (74.0) were from 2.5 to $3.5-\mathrm{kg}$, and 6 (2.8) were > $3.5 \mathrm{~kg}$.

In another study, Khalil et al., ${ }^{9}$ reported that the age mean of cases was 24.8 5.1-yrs. The median pregnancy was 2 , ranging between G1 \& G7. The mean pregnancy age depending on the ultimate menstrual period was 39.3-wks, ranging between 37 and 41-wks of amenorrhea. The mean embryonic delivery mass was $3.22320 .4235-\mathrm{kg}$ Closely $82 \%$ of cases were born vaginally, in comparison with $17 \%$ who were born via CS, and one woman was born vaginally via obstetric forceps.

Furthermore, Mittal et al., ${ }^{10}$ reported that a total of 335-cases have been involved in the report and have been monitored by DVE and trans-abdominal sonography to find out the FHP in the active $1^{\text {st }}$-stage (cervical dilation $40-60 \mathrm{~mm}$ ) and in the $2^{\text {nd }}$-stage of labour. The age mean of cases was 22.812 .91 -yrs. The majority of cases $(60.0 \%)$ had a mean BMI of $23.2511 .85 \mathrm{~kg} / \mathrm{m} 2$. The mean pregnancy age was 39.07 0.79-wks (37-42-wks). The interval of pregnancy was $39-39+6$ in $54.39 \%$ of females. The majority of delivered babies were from 2.5 to $3.5 \mathrm{~kg}$ [236 (70.45\%)], and $20.30 \%$ of delivered babies were of small birth mass.

In the current work, we revealed that the embryonic head position distribution in the study group females according to ultrasonography and DVE examination and the agreement between them. The embryonic head position couldn't be identified in 21 (24.7\%) of the females by the DVE examination. There was high agreement $(78.1 \%)$ between the two methods when the embryonic head location was LOA-Left Occiput Frontal. The intra ICC for both the US and DVE as regards embryonic head position revealed a high correlation (ICC, 0.669 95\% confidence interval, 0.492-0.785) and the accordance between DVE and the US was substantial $(=0.635$, P-value 0.001$)$.

Indeed, Mohan et al., ${ }^{7}$ reported that the embryonic head location couldn't be assessed by DVE in 44 out of $458(9.6 \%)$ observations because of the existence of a head. On the other hand, embryonic head location was assessed by trans-abdominal US in all patients. In 376 out of $458(82.1 \%)$ observations, the head location on the US was at $45^{\circ}$ of the DVE evaluation (Table 3). The accordance between the 2 methods was non-significantly associated $(=0.554 ; \mathrm{P}$ 0.001).

A local report in addition to a new multicenter random controlled study by Ramphul et al., ${ }^{11}$ have concluded that, in comparison to DVE, determining embryonic head position with US prior to instrumental birth decreases mis-placement of the vacuum cup. The prophecy of continual OP position at birth is also probable with a sensitivity of about $70-80 \%$.
Chou et al., ${ }^{12}$ concluded finding embryonic head location precisely in $71.6 \%$ of DVE vs. $92.0 \%$ of US assessments.

Hassan et al., ${ }^{13}$ found embryonic head location in 98 $\%$ of US assessments but only $46 \%$ of DVE assessments.

Akmal et al., ${ }^{14}$ and Souka et al., ${ }^{15}$ were unsuccessful in determining embryonic head location in $33.5 \%$ and $60.7 \%$ of DVEs, respectively. In the current work, embryonic head position was defined in a high percentage of DVEs in comparison to preceding research, perhaps as the mainstream of examinations in preceding reports have been done via midwifes, while all DVEs have been done via obstetricians in the current work. This is in accordance with research concluding that the rate of precise determination of embryonic location via DVE was high for obstetricians in comparison to midwives $(50 \%$ versus $30 \%)$.

Moreover, digital pelvic examinations are minor in the US for examining the embryonic head crosswise location throughout labour. In particular, the head succedaneum connected to the deep crosswise location reduces the diagnosing exactness of DVE. The crosswise location of the embryonic head could disturb the descent of the fetus via asynclitism. ${ }^{16}$

A new report by Malvasi et al., ${ }^{17}$ revealed that "squint signs" and "sun-set of thalamus and cerebellum signs" are two simple US signs for frontal and backward asynclitism, correspondingly. The commonest crosswise location was the left, whereas the commonest asynclitism was the frontal. The crosswise head locating with frontal or backward asynclitism is improbable to be indorsed by medication-or performance-connected mechanisms but must somewhat be a result of cephalopelvic disproportion. Moreover, epidural numbness doesn't increase the dystocic labour rate. ${ }^{18}$

In accordance with the classifications of the American College of Obstetricians and Gynecologists, the station splits the pelvis above and under the ischial spines into 5 th at $10-\mathrm{mm}$ pauses. Zero station means that the lowest embryonic giving part is at the plane of the spines. In the meantime, station +5 is the condition of the embryonic head being observable at the introitus. But, the digital examinations of embryonic head stations are undependable. ${ }^{16}$

et al., ${ }^{19}$ studied the dependability of digital examinations of embryonic head stations evaluated by 32 residents and 25 attending physicians utilizing a recently designed delivery simulator mannequin. The mistake rates of residents and attending physicians were $50-88 \%$ and $36-80 \%$, correspondingly. Moreover, head succedaneum, a procedure throughout labour, could as well delay precise digital assessment of the embryonic station. Consequently, objective measurements for the appointment and station in labour are needed.

On the other hand, in the current study, as regards the embryonic head station distribution in the studied group according to ultrasonography and DVE examination and the agreement between them, there 
was high agreement $(95 \%)$ between the two methods when the embryonic head station was $20-\mathrm{mm}$. The ICC for both US and DVE as regards embryonic head station revealed a high correlation (ICC, 0.980 95\% CI, 0.969-0.987) and the accordance between DVE and US was reasonable $(=0.378, P$-value $0.001)$.

\section{CONCLUSION}

The Intrapartum US is a simple method that expands the identification of ordinary and non-ordinary labour, permits objective measurements of delivery progress and provides a more systematic foundation for labour assessment. Moreover, the usage of the US is of crucial significance in the execution of a secure operative birth and could aid in predicting whether a vaginal birth will be successful or not. Additionally, intra-partum US was revealed to be an advantageous device for diagnosing labour progress in the active phase among term females. The accordance between DVE and US results was powerful for cervical expansion, and fair for embryonic head station and head location. The majority of labouring females concluded that the US is less upsetting and favored it over DVE for assessments of labour.

\section{REFERENCES}

1. Friedman E.The graphic analysis of labor. Am J Obstet Gynecol. 1954; 1568-1575.

2. Zhang J, Landy HJ, Branch DW, Burkman R, Haberman S, Gregory KD, et al. Consortium on Safe Labor. Contemporary patterns of spontaneous labor with normal neonatal outcomes: Consortium on safe labor. Obstet Gynecol. 2010; 116: 1281-1287.

3. Segel SY, Carre no CA, Weiner SJ, Bloom SL, Spong CY, Varner MW, et al. Eunice Kennedy Shriver National Institute of Child Health and Human Development Maternal-Fetal Medicine Units Network. Relationship between fetal station and successful vaginal delivery innulliparous women. $\mathrm{Am}$ J Perinatol. 2012; 29: 723-730.

4. Stitely ML, Gherman RB. Labor with abnormal presentation and position. Obstet Gynecol Clin North Am. 2005; 32: 165-179.

5. Hamilton EF, Simoneau G, CiampiA, Warrick P, Collins K, Smith S, Garite TJ. Descent of the fetal head (station) during the first stage of labor. Am JObstetGynecol .2016; 214: 360.e1-6.

6. Barber EL, Lundsberg LS, Belanger K, Pettker CM, Funai EF, Illuzzi JL. Indications Contributing to the increasing cesarean delivery rate. ObstetGynecol. 2011; 118.

7. Mohan A, Pratima M, Rekha B, Shabnam B. G, Jyotsana S, Usha M. Assessment of labor progression by intrapartum ultrasonography among term nulliparous women, $n t$ J Gynecol Obstet. 2019; 147: 78-82.

8. Kahrs BH, Usman S, Ghi T, Youssef A, Torkildsen EA, Lindtjørn E, et al. Sonographic prediction of outcome of vacuum deliveries: a multicenter, prospective cohort study. Am J Obstet Gynecol .2017; 217: 69.e1-10.
9. Khalil O, Elsayed E., Mahmoud A, Louay H. Z, Assessment of the progress of labor by the use of intrapartum ULTRASOUND, Alexandria Journal of Medicine. 2012; 48(4): 295-301.

10. Mittal P, Verma M, Bachani S. Correlation of Digital Vaginal Examination with Trans-abdominal ULTRASOUND to Assess Fetal Head Position during Active Labor. J South Asian Feder Obst Gynae .2019; 11(6):375-380.

11. Ramphul M, Ooi PV, Burke G. Instrumental delivery and ULTRASOUND: a multicentre randomised controlled trial of ULTRASOUND assessment of the fetal head position versus standard care as an approach to prevent morbidity at instrumental delivery. BJOG . 2014; 121:1029-38.

12. Chou MR, Kreiser D, Taslimi MM, Druzin ML, ElSayed YY. Vaginal versus ULTRASOUND examination of fetal occiput position during the second stage of labor. Am J Obstet Gynecol. 2004; 191:521-524.

13. Hassan WA, Eggebø TM, Ferguson M, Lees C. Simple two-dimensional ULTRASOUND technique to assess intrapartum cervical dilatation: A pilot study. ULTRASOUND Obstet Gynecol. 2013; 41:413-418.

14. Akmal S, Tsoi E, Howard R, Osei E, Nicolaides KH. Investigation of occiput posterior delivery by intrapartum sonography. ULTRASOUND Obstet Gynecol. 2004; 24:425-428.

15. Souka AP, Haritos T, Basayiannis K, Noikokyri N, Antsaklis A. Intrapartum ULTRASOUND for the examination of the fetal head position in normal and obstructed labor. J Matern Fetal Neonatal Med. 2003; 13:59-63.

16. Ahn, K. H., \& Oh, M. J. Intrapartum ULTRASOUND: A useful method for evaluating labor progress and predicting operative vaginal delivery. Obstetrics \& gynecology science. 2014; 57(6), 427-435.

17. Malvasi A, Stark M, Ghi T, Farine D, Guido M, Tinelli A. Intrapartum sonography for fetal head asynclitism and transverse position: sonographic signs and comparison of diagnostic performance between transvaginal and digital examination. $J$ Matern Fetal Neonatal Med. 2012; 25:508-512.

18. Malvasi A, Tinelli A, Brizzi A, Guido M, Laterza F, De Nunzio G. Intrapartum sonography head transverse and asynclitic diagnosis with and without epidural analgesia initiated early during the first stage of labor. Eur Rev Med Pharmacol Sci. 2011; 15:518-523.

19. Dupuis O, Ruimark S, Corinne D, Simone T, André $\mathrm{D}$, René-Charles R. Fetal head position during the second stage of labor: comparison of digital vaginal examination and trans-abdominal ultrasonographic examination. Eur J Obstet Gynecol Reprod Biol. 2005; 123: 193-197. 